\title{
SURVEY PAPER ON BEHAVIOUR OF MULTI-STORIED R.C.C. FRAME STRUCTURE
}

\author{
Mithilesh D. Kapse ${ }^{1}$, Rakesh R. Shinde ${ }^{2}$ \\ ${ }^{1}$ P.G. Student, Civil Engineering Department, Late G.N. Sapkal College Of Engineering, Maharashtra, India \\ ${ }^{2}$ Assistant Professor, Civil Engineering Department, Late G.N. Sapkal College Of Engineering, Maharashtra, India
}

\begin{abstract}
The paper gives the idea about different researches carried out on multistoried building considering various parameters. All previous studies, observations, and conclusions show that the most of the part of lateral load on multi-storied building is carried by the in-filled wall and the shear wall. The result from a previous experiment expressed that these two components of building increase the stiffness and strength of the structure. The scope of present work is to analyze behaviour of multi storied building of different type of structural system like bare Frame system, Infill Frame system, shear wall orientation, tube type system. Analysis can be carried out by using any type of finite element software like SAP2000, ETABS software, STAD Pro, ANSYS etc. These models will then examine for different parameters like storey drift, lateral displacement, story shear and axial force in columns, time period variation under both static and dynamic loading.
\end{abstract}

Keywords: Framing system, Lateral loading, Response spectrum analysis, Stiffness.

\section{INTRODUCTION}

The lateral loads are almost live loads, whose main horizontal force component acting on the different members of structure. The lateral force effects due to wind and earthquake loads are usually analyzed as an equivalent static load in most type of high raised buildings. These buildings are designed in such a way that its every component must resist two types of loads, i.e. vertical Load due to gravity, and lateral load due to earthquake and wind. The components of horizontal framing system are slab and beams, which transfer vertical load to vertical framing system and in the vertical framing system there are beams and columns, which transfer lateral load to the foundation. The present study is an introductory report on the behavior of different kinds of multi storied buildings in different orientation, when they are subjected to the lateral loads. It highlights the different component parts of various previous studies carried out by many authors.

\section{TERMINOLOGY}

\subsection{Wind Loads}

One of the most common lateral loads is a wind load. It acts externally and the magnitude of force is directly proportional to the overall height and shape of the structure. The structure should be designed such that the effective surface area to wind must be as less as possible. The wind creates positive pressure on the windward side and a negative pressure on the leeward side when the building resists it. Some of the factors that affect the wind load include the geographical conditions, height, surface area of explosion, nearby structures, building shape and size, winds direction, wind velocity and pressures due to architectural design. All such factors are note into consideration when the lateral loads on the facades are calculated. It will be noted that wind loads, as well as the pressure developed upon wall and roof elements, should be static and uniform. Also, as a height of building increases, the pressure also increases.

\subsection{Earthquake Loads}

Earthquake loads are causes more damage than wind loads. It is occurs frequently in certain regions. It is a sudden lateral movement in ground under a structure that may shift in any direction and the horizontal components of this movement generates a wave action which usually transferred vertically to a structural. The variations in earthquake load are almost consistence than the wind load. The magnitude earthquake load changes with change in the stiffness, mass of the structure, and the motion of the earth surface because of seismic forces. These lateral forces can be resist by any structure by modifying location of building, importance factor, type of soil, and achieving good construction practices.

\subsection{Axial Force}

It is the load acting through the center of gravity of the member along its length. These are of two types, tensile forces and compressive forces. Both the forces are in opposite in direction so are denoted as positive and negative force in diagram. Also when the force passes through the geometric center of member, it will term as concentric force otherwise eccentric force.

\subsection{Bending Moment}

It is the resistive moment induced into member when loaded with external loads. These are of two types i.e. sagging moment and hogging moment which are referred by different signs. Also the bending moment becomes zero at point of contra flexure where the shear force is maximum.

\subsection{Story Drift}

Story drift or Lateral drift is the term given to horizontal sway of two adjacent stories of a building because of lateral forces. 
Drift is due to both flexural and shear, due to the axial deformations of column and to the diagonal deformations of beams, simultaneously. The term helps to the structural engineers to design building Models and can recommend the levels of strength and safety of structure. It also helps to study the variations of the rigidity of each story at various levels. The different features like mass, stiffness, and stresses acting on the structure will affect the behaviour of overall structure. Evaluation of such parameters on the dynamic Behavior of the structures has to be study properly. In low raised buildings, the contribution of lateral forces is not much significant to the shear mode property of building. But in tall structures the higher axial forces and deformations in the columns effects over a large height, cause the bending of structure and displacement to noticeable.

Story drift ratio is the relative difference of design displacement between the top and bottom of a story, divided by the story height. Generally, the design story drift ratio does not exceed 0.005. IBC sets the maximum drift for normal buildings at between $0.7 \%$ and $2.5 \%$ of storey height.

The high raised structure must behave as ridge or at least semi ridge structure to withstand the lateral forces and to retain the non-structural elements on it such as walls, claddings. If the deformation of structure if more, it will leads to failure of claddings and even overall storey too. The displacement is directly varies with the material property of the frame. The low stiffness of moment-resisting frames results to chances of high storey drifts.

\subsection{Storey Displacement}

The floor displacement profile is maximum with the maximum story drift ratio depending upon the height, the time period, and the column-to-beam strength ratio. It is measured in terms of mean coefficient of variation. The parameters under which displacement is study are sections and variations in of reinforcement. This term is proportional with the mechanism of formation of plastic hinges in structural members.

\subsection{P-Delta Analysis}

It is the method of determination of the secondary shear related with its horizontal displacement occurs at the vertical members of structure having axial load. The results of "PDelta" depends upon the intensity of axial force on vertical member, height between fix end and free end of member, and time.

\subsection{Response Spectrum Method}

The analysis is useful for determine the peak value of ground acceleration in case of seismic analysis of structure. The curve is plotted between ground motion and frequency. For which different damping ratios were considered and the mean peak response of displacement, velocity, acceleration of structure with time period is then calculated from different curves (i.e. spectrums). Different factors that will affects the response spectrum analysis are energy release mechanism, soil condition, Richter magnitude, damping in the system, time period of the system.

\section{EXPLORATON}

The details of different framing system which are considered under this study are mentioned below:

\subsection{The Bare Frame}

The bare frame is basically a moment resistant and rigid jointed frame, which consists of beams and column only. Analysis of Bare Frame system is considered when the structure is under construction phase. When the outer walls of building are replaced by the glazing-panels (e.g. Glass panel, acrylic wall panel, fiber glass panels, PVC panels, polycarbonate panels, polyethylene panels) the frame will act as bare frame. Also, if the floors of the structure as precast members and connected partially with beams and columns, this type will know as bare type frame.

\subsection{Infill Wall Frame}

Infill wall means partition wall which is made up of masonry work. Infill walls are of various types such as brick masonry infill wall, concrete infill wall, timber framed infill walls, light steel framed infill walls. The infill material should be such that it should not participate in transmission of any overcoming loads to the structural system. But the observations and analysis results indicates that the use of masonry infill walls constructed in between the adjacent columns of reinforced concrete framed structures plays major role in the damage of component parts and collapse of buildings during strong earthquakes. This may be because of the use of heavily denser masonry material. Much site evidence has shown that the infill masonry which having low unit weight can help to considerably reduce the injury of a reinforced concrete structure. Because of the Infilling of material in between columns it results in extremely high shear force in columns due to horizontal component of the force in equivalent diagonal strut of masonry. That resulted in failure of columns in infill frames in many past earthquakes. But while designing the building frame, infill wall is not considered as a structural element. Due to this, stiffness of infill wall is not estimated and not considered in design of structure.

\subsection{Shear Wall Frame}

Now-a-days in most of the tall structures, shear wall is the most commonly used lateral load resisting member. Shear wall has plane stiffness and strength which can be used to resist large lateral load and supports vertical load. Shear walls provides the required lateral strength to the structure which resists horizontal earthquake forces. Shear walls are require to transfer these horizontal forces to the adjacent element in the which carries load, like another shear wall, beams, slabs or floors, retaining walls, or even footings. Shear walls also resist the horizontal load and provide lateral stiffness to prevent the roof or floor above from exceeding sway. Also, those buildings which are sufficiently stiff will usually prevent non-structural damage. 


\subsection{Framed Tube Structure}

The tube structure is the building system designed to resist heavy lateral loads due wind, seismic, etc. in which a building is act like a hollow cantilever cylinder. It is verified that the frame system can be constructed using, reinforced concrete structural steel, or composite construction of both. The frames consist of closely spaced columns, generally $2-4 \mathrm{~m}$ spacing in between centers of adjacent column, joined by deep girders at slab level of each floor. The idea is to create a tube that will act like a continuous perforated chimney or stack. This exterior framing is designed sufficiently strong to resist all lateral loads on the building, hence the remaining interior part of the building to be simply framed for gravity loads. It had been proved that the tube structure is the system has ability to resist overturning due to lateral loads.

When lateral loads act, the outer portion of frames aligned in the direction of loads which will act as the webs of the massive tube cantilever having one end fixed to ground and for perpendicular to the direction of the loading. This results in the middle face of flange columns bring under less stressed than the columns at corner and hence their contribution into potential lateral strength is less.

\section{DISCUSSION AND RESULTS}

The following are summary of some literature review referred from different publication which describes the geometry of models, area of research, method of analysis and their respective results.

Reference [3] shows, the paper which presents the lateral load carrying capacity of system in which an L-shaped G+40 storied R.C.C. framed building located in Seismic Zone III and is assume on hard type soil, which has dimensions as $128.2 \mathrm{~m}$ in height $47.82 \mathrm{~m}$ in length and $31.45 \mathrm{~m}$ in width. The models are analyzed by Static Method and Dynamic method (Response Spectrum method). The models have been analyzed by using ETAB software. Following models are considered.

Model I: Regular column /wall, beam slab system

Model II: Replacing the beams and columns with Modular wall slab system for residential floors.

Form their studies it gives results show the parameters like story drift, lateral displacement and time period is less in model-II as compared to model-I. From all the results, it is concluded that model II is very effective in resisting the lateral forces induced by Earthquake. Due to the box effect of modular type scheme, it is increases the overall stiffness of the building frames thus, reducing the sway problem in the structure.

Reference [4] shows, the paper which presents the effect of the infill material on the overall behavior of the structure. All previous related studies show that infill materials considerably interferer in affect the seismic performance of the in-filled frame structures. The study aimed on the effect of different types of infill materials on the seismic performance of infilled RC frames compared using SAP2000 and Axis software.
Following models are considered with different density of infill materials:-

Concrete $\left(25 \mathrm{KN} / \mathrm{m}^{3}\right)$, Brick $\left(27 \mathrm{KN} / \mathrm{m}^{3}\right)$, A.A.C. $\left(11 \mathrm{KN} / \mathrm{m}^{3}\right)$, Flexy Brick or Polyurethane sandwiched brick $\left(1.8 \mathrm{KN} / \mathrm{m}^{3}\right)$

The main conclusion is that, the behavior of reinforced concrete frame structures can be improved by changing the material characteristics of the infill. The infill material should possess low density and also should not take part to transmit load to the structural system.

Reference [5] shows, high raised steel structure in seismic region. Analysis is carried by using ETAB software. Structural frame where modeled as single 3-D space frame, three independent degree of freedom are permitted at each level. Each floor was treated as diaphragm rigid in its own plane.

The model was analyzed for considering wind force perpendicular to the orthogonal faces of structure, the equivalent static forces where calculated based on applicable codes and the response spectra including acceleration, velocity, displacement for lower level and upper level of earthquake.

In result it is concluded that, the multiple framed tube concept can be effectively utilized in the seismic region. Also properly proportioned framed member will result economic structure with strength, stiffness and ductility prescribed in current building codes.

Reference [6] shows, the paper describes three types of irregularities in building according to mass, stiffness, geometry of building. Response spectrum analysis (RSA) was conducted for each type of irregularity and the storey shear forces obtained were compared with that of a regular structure.

The results where summarized as follows:-

According to results analysis of response spectrum, the storey shear force is maximum in first storey and minimum in the top storey in all cases. For mass irregular building frames base shear is greater than stiffness irregular building. From time history analysis, the displacements of geometry irregular buildings were found to be greater than that in case of regular building for upper stories but decreases as move to lower stories. It also concluded that, the natural frequency for high raised structures have low hence their response was found to be maximum in a low frequency earthquake.

Reference [7] shows, dynamic linear analysis using response spectrum method is performed and lateral load analysis is done for structure without shear wall and structure with shear wall. A residential building of $\mathrm{G}+15$ irregular structures having the base dimension of plan $24.38 \mathrm{~m} \times 25.98 \mathrm{~m}$ with a stilt floor of height $4 \mathrm{~m}$ and typical floor of height $3 \mathrm{~m}$ is considered for the analysis. The building structure built with concrete with cement-fly ash brick infill wall. Geometry of the building for the column as least lateral dimension of $300 \mathrm{~mm}$ and minimum width of main beams as $400 \mathrm{~mm}$ is considered. Analysis is carried by using ETAB software. 
The result shows that lateral forces are reducing when the shear walls are added at the specific locations of frames. Hence, it is shows that shear walls are more resistant to lateral loads in an irregular structure and also effects of torsion.

\section{CONCLUDING REMARKS}

The paper present the summary of behaviour the different system of building frames under the action of lateral force and introduce the lateral forces for which they have to overcome. The paper helps the research persons for further work and a study in this filed and enables them to choose their mode of research work.

\section{REFERENCES}

[1]. Syed Azmat Ali Shah: "Behavior of Infill Walls under Lateral Loads in Reinforced Concrete Frames - A Review" International Journal of Advanced Structures and Geotechnical Engineering

[2]. Prof. S.R.Satish Kumar and Prof. A.R.Santha Kumar: "Design of Steel Structures" (NPTI) Indian Institute of Technology Madras.

[3]. Deepak Suthar: "High Rise Structure Subjected To Seismic Forces And Its Behavior"

[4]. Ioana Olteanu: "Influence Of Infill Material On The Overall Behavior of A Reinforced Concrete Frame Structure"

[5]. Navin R. Amin : "Design Of Multiple Framed Tube High Raised Steel Structure In Seismic Region"

[6]. Ankesh Sharma : "Seismic analysis and design of vertically irregular RC building frames"

[7]. Ravikanth Chittiprolu : "Significance of Shear Wall in High rise Irregular Buildings"

[8]. Chris H. Luebkeman and Donald Peting Architectonic: "The science of architecture" 